\title{
AS POSSÍVEIS CONTRIBUIÇÕES DO ENSINO DE CIÊNCIAS PARA A IDENTIDADE DO ENSINO FUNDAMENTAL II E PARA A TAREFA DE ALFABETIZAR
}

\section{Possible contributions from science education for the identity of the elementary school II and the task of literacy}

José Alves da Silva ${ }^{1}$

Resumo: Discutimos a identidade do Ensino Fundamental II a partir de consultas a documentos oficiais e a algumas pesquisas sobre o tema, e apontamos a tarefa da alfabetização - ainda que com enfoque diferente daquele empreendido no Ensino Fundamental I - como um possível elemento definidor dessa identidade. Como o conceito de alfabetização não é consensual, utilizamos a proposição do domínio dos signos e dos códigos proposto pelo semiólogo e filósofo francês Roland Barthes, o qual prevê forte dose de emoção e subjetivação nesta tarefa; além de levarmos em consideração as características da sociedade pós-industrial que afetam a todos nós, sobretudo os nossos alunos. Com isso, realizamos um exercício teórico acerca de como o Ensino de Ciências, em suas especificidades, pode contribuir tanto para a própria sedimentação dessa identidade, quanto para a ação alfabetizadora nesse nível de ensino.

Palavras-chave: Alfabetização. Ensino Fundamental II. Ensino de ciências. Roland Barthes. Identidade.

\begin{abstract}
We discuss the identity of Elementary School II from official documents and researches on the subject and point out the task of literacy - though with a different approach from that undertaken in Elementary School I - as a possible defining element of that identity. As the concept of literacy is not consensual, we use the proposition in the domain of signs and codes proposed by the French philosopher and semiotician Roland Barthes, which provides a strong dose of emotion and subjectivity into this task, besides taking into consideration the characteristics of post-industrial society that affect all of us, especially our students. And so on, we conducted a theoretical exercise about how science teaching, in its specialist areas, can contribute to this identity, and enhance literacy at a basic educational level.
\end{abstract}

Keywords: Literacy. Elementary school II. Science education. Roland Barthes. Identity.

\footnotetext{
${ }^{1}$ Universidade Federal de São Paulo (Unifesp), Departamento de Ciências Exatas e da Terra, campus Diadema, SP, Brasil. R. Prof. Artur Riedel, 275, Eldorado, CEP 09972-270, Diadema, SP, Brasil. E-mail:

<josealves.unifesp@gmail.com>
} 
Silva, J. A.

\section{Sobre a identidade do Ensino Fundamental II}

Apesar de haver outros objetivos para o Ensino Fundamental (inclusão e ensino para a cidadania, apenas para citar alguns exemplos), uma interpretação possível, adquirida após seguidas consultas a documentos oficiais (Lei 9.394/1996 de Diretrizes e Bases da Educação Nacional - LDB/1996) (BRASIL, 1996), pode ser aquela que aponta para a tarefa de seguir alfabetizando os alunos de suas séries. Acredita-se que um bom domínio da leitura e da escrita é fundamental para a vida dos estudantes - e aqui incluímos sua desenvoltura no mundo profissional, social e, até mesmo, afetivo.

O Ensino Fundamental costuma ser divido em duas grandes etapas: o Fundamental I, compreendendo alunos com idade entre seis e dez anos, em que as turmas comumente ficam a cargo de um professor polivalente; e Fundamental II, que abarca alunos entre 11 e 14 anos de idade, no qual as disciplinas costumam ser ministradas por professores especialistas. Essa divisão ocorre muito mais por razões históricas (BEISIEGEL, 2006), administrativas e culturais do que propriamente por aspectos legais - a LDB/1996 ora vigente, por exemplo, não faz formalmente essa separação. Entretanto, assumindo que, na prática, tal separação existe, é razoável supor que há diferenças nesses dois níveis de ensino. E, se há diferenças, podem ser úteis alguns exercícios para clarear suas identidades (aqui compreendidas como "conjunto de características próprias de uma pessoa, um grupo etc. que possibilitam sua identificação ou reconhecimento" (AULETE, 2008). Um desses exercícios pode ser o de, por exemplo, investigar seus objetivos principais.

Em particular no Fundamental I, embora existam conhecimentos historicamente trabalhados em cada uma das séries, os mesmos vêm atrelados ao objetivo da alfabetização o que é muito saudável. O Ensino de Ciências ou de História, por exemplo, passam quase sem serem percebidos enquanto áreas do conhecimento, ao passo que o ensino das quatro operações elementares e a competência leitora e escritora adquirem função fulcral nesse nível de ensino.

Entretanto, em geral, pouco se discute sobre os objetivos do Ensino Fundamental II a partir de suas especificidades, estando sua identidade pouco clara. Segundo alguns documentos - como os Parâmetros Curriculares Nacionais do Ensino Fundamental (BRASIL, 1998) esses objetivos em pouco se diferenciam do Fundamental I, salvo algum cuidado com o amadurecimento cognitivo - e gradativo - do aluno. Essa falta de clareza parece sugerir que deve ocorrer apenas um maior aprofundamento no que se refere ao conhecimento a ser trabalhado em suas séries. Contudo, uma leitura mais atenta aponta que o principal objetivo deveria ser o de seguir na tarefa da alfabetização.

Talvez essa falta de clareza tenha sido uma das causas para o Ensino fundamental II ter se constituído como um espaço para a aprendizagem de alguns conhecimentos historicamente ensinados, oriundos da organização intrínseca das áreas, quase naturalizados, os quais, muitas vezes, sequer são aqueles propostos pelos Parâmetros Curriculares Nacionais. Assim é que, na complicada entrada na primeira série do Fundamental II ${ }^{2}$ (CASARIN, 2008; MENIN, 1994; SILVA, 1997), a situação se modifica drasticamente em relação ao nível anterior: os professores,

${ }^{2} \mathrm{~A}$ antiga quinta série, atual sexta série, fenômeno educacional já amplamente estudado. 
As possíveis contribuições do ensino de ciências ...

antes polivalentes, passam a ser especialistas em suas disciplinas - alguns sentem-se desobrigados da tarefa de seguir no processo de alfabetização. Por isso, priorizam o ensino do conhecimento específico e não o colocam a serviço do desenvolvimento da leitura e da escrita de seus alunos. Esse fato, provavelmente, tem sua origem na antiga divisão primário e ginásio (BEISIEGEL, 2006), na qual preponderava o objetivo eminentemente propedêutico do atual segundo nível da Educação Básica.

Como esse objetivo eminentemente propedêutico é uma realidade distinta da de hoje (MENEZES, 2001), tais conhecimentos tendem a ser trabalhados de maneira descontextualizada e inócua, frente a alunos que não dominam minimamente os signos e códigos (BEISIEGEL, 2006) e que não estão abertos à ocorrência da aprendizagem, pelo menos nos moldes tradicionais. Isso porque estamos na sociedade pós-industrial, em que aprender - tarefa que exige esforço, dedicação e disciplina (FREIRE, 1996) - talvez tenha se tornado mais difícil. Aqui, referimonos às características gerais da sociedade pós-industrial, em que o desprezo ao rigor, à concentração, à disciplina, ao silêncio e o culto ao hedonismo afetam aos alunos e a nós todos (AMARAL, 1997; HABERMAS, 2002; LIPOVETSKY, 2002, 2004, 2005, 2007a):

A segunda fase do consumo, que surge por volta de 1950, designa o momento em que produção e consumo de massa não mais estão reservados unicamente a uma classe de privilegiados; em que o individualismo se liberta das normas tradicionais; e em que emerge uma sociedade cada vez mais voltada para o presente e as novidades que ele traz, cada vez mais tomado por uma lógica da sedução, esta concebida na forma de uma hedonização da vida que seria acessível ao conjunto das camadas sociais. (LIPOVETSKY, 2004, p. 24)

Acrescente-se a esse rol de características, a espetacularização dos fatos, dos processos e, até mesmo, das relações, bem como o aumento do individualismo, conforme aponta uma das principais obras que discute o assunto:

O mundo presente e ausente que faz ver é o mundo da mercadoria dominando tudo o que é vivido. E o mundo da mercadoria é assim mostrado como ele é, pois seu movimento é idêntico ao afastamento dos homens entre si e em relação a tudo o que produzem. (DEBORD, 1997, p. 28, grifos do autor)

A discussão em torno da sociedade pós-industrial ${ }^{3}$ vem ganhando espaço em diversas áreas do conhecimento, inclusive na Educação. Embora não se trate de tema recente, é de discussão complexa e pouco consensual, mas fundamental para compreender os tempos atuais e, especificamente, o recorte deste trabalho.

\footnotetext{
${ }^{3}$ Preferimos esse termo ao de pós-modernidade, dada a polêmica em torno do tema - alguns seguidores de Theodor Adorno (1903-1969), por exemplo, preferem chamá-la de modernidade em grau máximo.
} 
Silva, J. A.

Há, portanto, um desencontro entre o que a legislação propõe para o Fundamental II, o perfil de seus alunos imersos nessa sociedade e a expectativa e posterior ação de seus professores, o qual resulta em um ambiente de aprendizagem caracterizado pela ausência de diálogo entre aluno-professor, aluno-conhecimento, professor-turma, entre outras possibilidades.

O quadro descrito até aqui não configura nenhuma novidade, por se tratar de fenômeno já amplamente estudado (AMARAL, 2006; MENEZES, 2005; SILVA, 2008). Interessa-nos, neste artigo, aprofundarmo-nos em como o Ensino de Ciências se insere nele, ora agravandoo, ora sendo afetado. Buscamos refletir sobre quanto as especificidades do Ensino de Ciências podem minimizá-lo, sobretudo no que se refere à difícil tarefa de seguir alfabetizando.

\section{O papel do Ensino de Ciências no Fundamental II}

O quadro de falta de diálogo no Fundamental II atinge diretamente as aulas de Ciências, a começar pelo fato de que o imaginário social acerca do cientista é fomentado por estereótipos em que estão presentes conhecimentos - considerados difíceis - e que são mais bem desenvolvidos por pessoas com comportamentos objetivos e práticos, distantes da vida social, entre outras expressões de senso comum (MELO; ROTTA, 2010; PÉREZ et al., 2001). A tarefa de alfabetizar, pois, não faz parte da cultura de educadores em Ciência, passando ao largo de suas preocupações ${ }^{4}$.

Carl Sagan (1996), lendário divulgador de Ciências, em seu livro O mundo assombrado pelos demônios, mostra como uma sociedade desinformada em Ciências desperdiça investimentos e passa a correr grandes riscos em seu funcionamento. No mesmo livro, analisa a deficiência no ensino de Ciências nos Estados Unidos, apontando-o como desestimulante e, até mesmo, como responsável por construir, juntamente aos alunos, uma "pseudociência", posto que é colocada como um produto "acabado", praticamente não questionável, quase dogmático, em suma, tudo o que a Ciência não é (SAGAN, 1996, p. 250; 370).

Sagan sustenta que, para ser Ciência, é preciso haver questionamentos sobre o que se estuda, deve haver muitas comprovações, generalizações das explicações e muita observação. É assim que a Ciência costuma ser produzida: basta observar os rigorosos critérios para publicar um artigo científico ou uma tese, ou, ainda, os numerosos e imprescindíveis congressos, simpósios e encontros sobre os mais variados temas científicos. Segundo ele, a credibilidade de um conhecimento em Ciência advém, grosso modo, do fato de ter passado por esse rigor e da

\footnotetext{
${ }^{4}$ Aqui, diferenciamos o conceito de alfabetização presente neste trabalho em relação àqueles relativos à alfabetização científica, cujos objetivos encontram-se mais próprios de leitura de mundo para transformação direta da sociedade: “[...] seria desejável que os alfabetizados cientificamente, não apenas tivessem facilitada a leitura do mundo em que vivem, mas entendessem as necessidades de transformá-lo, e transformá-lo para melhor" (CHASSOT, 2000, p. 34); bem como daqueles pesquisadores que vêm apontando bons caminhos relativos ao Ensino de Ciências e à leitura e à escrita, com trabalhos envolvendo textos em salas de aula. Como exemplos, citamos: Almeida e Ricon (1993), Kawamura e Salém (1996), Silva (2002), Zanetic (1998), dentre outros. Neste artigo, pretendemos enfocar a questão do domínio de códigos e signos e dos fortes componentes subjetivos presentes na tarefa - daí a escolha por Roland Barthes - no seio da sociedade pós-industrial.
} 
garantia da aceitação de um resultado por toda uma comunidade de especialistas, ainda que haja um indefectível e saudável espaço para questionamentos e que continuem a ocorrer erros, a despeito de todo esse cuidado. Há, portanto, um processo que costuma ser rigoroso e minucioso em sua análise - o que não significa julgá-lo estanque, infalível ou imune a outros interesses (econômicos, individuais, etc.).

Por isso, ensinar Ciência não é somente trabalharmos com a informação científica (os antigos conteúdos programáticos). É, pois, ensinarmos como é construída, produzida e difundida, como é utilizada socialmente, seus riscos e benefícios, quanto - e como - é necessário controlá-la socialmente, entre outros aspectos. Os próprios Parâmetros Curriculares Nacionais do Ensino Fundamental (BRASIL, 1998) e do Ensino Médio (BRASIL, 1999) propõem essa concepção de ensino. $\mathrm{Na}$ compreensão desse processo de funcionamento da Ciência como produção humana, a questão do rigor é primordial ${ }^{5}$, o qual vem acompanhado de: uma disciplina do pesquisador ou do grupo de pesquisa, concentração, dedicação, prazer no momento das descobertas, inquietações, angústias, inseguranças, reflexões, envolvimento afetivo, entre outras ações humanas.

Cabe-nos perguntar qual o atrativo que essa maneira de trabalhar apresenta aos jovens que vivem na chamada sociedade pós-industrial, em que se cultua, em demasia, o hedonismo e o prazer imediato, em que a rapidez tem primazia em relação ao cuidado e ao rigor, em que a busca por conhecimentos em Ciência básica é desprezada em detrimento da ideia imediatista de que é preciso ter uma utilidade - principalmente econômica - para justificar um investimento; em que todos nós temos dificuldades em convivermos com o silêncio, com a disciplina e com o esforço, quiçá recompensados ao longo prazo (SILVA, 2011).

O enfrentamento dessas questões trazidas pela sociedade pós-industrial pode ser feito, também, na escola, à medida que se priorizam aspectos voltados ao resgate de um ideal coletivo de pertencimento à sociedade e quiçá à própria espécie, conforme aponta o próprio Lipovestky (2007b, p. 6):

\begin{abstract}
No tocante à educação, penso que não podemos fazer uma educação de leveza. Educar uma criança ou formar um ser humano não é algo que se deve fazer com um culto da leveza; é preciso incutir-lhes responsabilidades e dar o gosto de realizar as coisas. Assim, há uma parte do homem que é leve, mas há também uma parte que Nietszche chamou de "vontade de potência". O desejo de potência não é a guerra, mas o desejo de se ultrapassar, de fazer melhor, de ir sempre mais longe, no trabalho, na criação, na invenção... Hoje, as escolas, os pais, a educação, enfim, devem beneficiar essa vontade de potência, quer dizer, fazer com que as pessoas tenham paixões - e as paixões não são leves! - para realizar coisas e não simplesmente para consumir.
\end{abstract}

${ }^{5}$ É importante deixarmos claro que esse rigor não abarca a pretensão de que é sempre possível dar conta de todas as variáveis de um problema e de que não haja limitações no resultado. 
Silva, J. A.

Levando-se em consideração essa proposição de Lipovestky (2007b), o Ensino de Ciências pode, verdadeiramente, contribuir para o processo de alfabetização, uma vez que ensinar Ciência significa ter de lidar, o tempo todo, com o rigor, seja em observações criteriosas de um fenômeno, na sua explicação (em que os cuidados com os conceitos sejam imperiosos), no ato de descrevê-lo sob uma sequência organizada de etapas, com procedimentos como: observação, hipóteses, conclusões, tentativas de generalizações, possíveis novos questionamentos, e assim sucessivamente (sem que, necessariamente, ocorram nessa ordem).

$\mathrm{O}$ ato de ler e de escrever deve ter como pano de fundo esse rigor. Se, no Fundamental I, cabe ao educador ser extremamente cuidadoso no ato de alfabetizar, ainda que se permita ser maleável frente aos diferentes tempos de aprendizagem da criança e às suas diferentes etapas do processo de alfabetização, caberá, no Fundamental II, agir nesse processo de alfabetização lidando com as minúcias, com a acuidade, com a organização mental que uma boa leitura ou produção de textos demandam, ensinando a depurar uma produção escrita, algo que vai muito além do simples domínio do signo (TEIXEIRA, 1999).

O mesmo Sagan (1996), em seu artigo $A$ anticiencia, afirma que um povo antigo pode ter uma leitura astronômica que lhe serviu perfeitamente para as suas atividades agrícolas em uma determinada localidade, a qual um grupo de meteorologistas sequer conhecerá um dia. Tal leitura tem o seu valor e deve ser respeitada como conhecimento. Porém, diferentemente daquela dos cientistas, provavelmente não servirá para prever o tempo em qualquer lugar do mundo caso utilizássemos os seus critérios. Da mesma maneira, o domínio dos signos já previamente estabelecidos na maioria dos alunos que terminam o Fundamental I tem o seu valor, mas ainda está longe de ser uma tarefa acabada. Não os faz alfabetizados ainda. Para conseguir, de fato, dominar o ato de ler e de escrever, o uso sistemático do rigor e do cuidado na leitura e na escrita deve ser incorporado a sua execução, ao mesmo tempo em que é por meio do desenvolvimento desse rigor que se aprende melhor a ler e a escrever - ele $^{6}$ é, pois, meio e fim.

Assim é que os professores de Ciência podem ajudar na tarefa de alfabetizar porque podem incorporar o ensino do rigor, absolutamente necessário à Ciência, às práticas do aluno do Fundamental II. Contudo, é preciso deixar claro que compreensão de alfabetização poderia ser adotada para empreender essa ideia.

\section{A alfabetização e os procedimentos da Ciência}

Não é de todo despropositado comparar o processo de alfabetização ao da construção do conhecimento. Para aprender o significado de um signo, a criança deve observá-lo cuidadosamente em suas minúcias, reproduzi-lo algumas vezes (se for o caso), concentrar-se em sua fonética, observá-lo em outros locais além da escola, familiarizar-se com ele, generalizálo. Esse processo é permeado por forte dose de emoção: há muita insegurança fruto de um

${ }^{6} \mathrm{E}$ importante não confundir o rigor defendido neste artigo com rigidez disciplinar ou com aulas em que o silêncio seja sempre o elemento preponderante. Referimo-nos ao cuidado, ao desenvolvimento da acuidade e da percepção das eventuais sutilezas presentes no objeto estudado (CRITELLI, 2002). 
As possíveis contribuições do ensino de ciências ...

estranhamento inicial, por parte da criança, diante do signo, há o desafio para enfrentá-lo, surge um sentimento de segurança e de prazer ao dominá-lo e aplicá-lo a outras realidades (AMARAL, 2006).

É razoável supor, então, que a tarefa de alfabetização não se esgota apenas com o domínio dos signos e dos códigos. O filósofo e semiólogo francês Roland Barthes, em um de seus estudos sobre a escrita, ilustra quanto a tarefa de ler e de escrever vai além disso:

\begin{abstract}
Não tenho relações neutras com o signo: sempre fui apaixonado pelas operações de deciframento dos signos nas sociedades ou na literatura. É preciso acrescentar que essa relação é ambivalente: há um momento em que os códigos me liberam porque são geradoras de segurança. As sociedades como as nossas, muito alienadas, angustiadas, precisam da clareza dos signos, de sua permanência para se sentirem seguras. Um código bem feito sempre tranqüiliza, mesmo que seja coercitivo. Mas, ao mesmo tempo, os signos me oprimem muito facilmente. As linguagens ou as sociedades que naturalizam os signos me são intoleráveis, elas vivem os signos, mas recusam expô-los como tais. Noutras palavras, elas não vivem os signos por aquilo que são: produtos históricos, elaborações ideológicas do sentido. (BARTHES, 2004, p. 221)
\end{abstract}

Levando-se em consideração essa concepção, é possível tecermos algumas análises sobre o processo de alfabetização em grande parte das escolas brasileiras. O pesquisador Celso de Rui Beisiegel (2006) sustenta que os alunos tidos como analfabetos que chegam ao Fundamental II apresentam graves deficiências de leitura e de escrita, as quais comprometem o prosseguimento de sua vida escolar. Entretanto, na verdade, segundo o mesmo pesquisador, dominam minimamente os signos, estando, pois em etapas anteriores de alfabetização, salvo algum caso mais grave. Essa constatação foge do senso comum.

Se juntarmos esse grupo de alunos, que realmente exige atenção especial (de uma escola, de um professor ou de um sistema de ensino), ao hegemônico grupo de alunos e de pessoas que escrevem e leem mal em nossa sociedade, veremos que, na verdade, não há problemas unicamente de dificuldade no deciframento do signo. Há um quadro de pouco desenvolvimento da leitura e da escrita, quase sempre consequência (ou causa?) de: uma aparente dificuldade de organizar ideias, uma falta de capacidade de concentração e de memorização para o código, falta de hábitos de leitura, em suma, (também) falta de rigor no ato de ler e de escrever.

Em nossas salas de aulas, é comum percebermos alunos que copiam errado uma palavra da lousa ou de um livro, ou que jamais utilizam a pontuação em seus textos, ou escrevem de uma maneira aleatória (sem organização do texto), ou, ainda, que jamais utilizam qualquer acentuação ${ }^{7}$. Tais falhas não são coibidas com a importância que merecem (salvo

\footnotetext{
${ }^{7}$ Vale dizer aqui que não são somente os alunos que não estão utilizando pontuação e acentuação. Essa falta de rigor está disseminada em quase toda a sociedade. É possível que os tempos de Internet estejam acentuando esse quadro.
} 
Silva, J. A.

raras exceções ou, unicamente, pelo professor de Português em tarefas que exijam explicitamente o olhar para a escrita). Os professores das outras áreas não consideram a eliminação desses erros um elemento prioritário. Cabe salientar que não estamos nos referindo unicamente à correção ortográfica ou sintática (que são absolutamente imprescindíveis), mas àquilo que Barthes defende como domínio dos signos e códigos.

A não-preocupação generalizada em relação a esse cuidado é fruto, também, da maneira pela qual se costuma ensinar. Se as aulas são baseadas somente em cópias de lousa ou de livros, ou de cunho exclusivamente expositivo, ou permeadas por resoluções de questionários cujas respostas vêm facilmente de uma leitura "maquínica" (SILVA, 2008, p. 180) de um texto didático - seguido de uma prova sobre esse questionário - não haverá espaço para aprimorar a leitura e a escrita do aluno. Sequer haverá espaço para permitir sua reflexão e capacidade leitora e escritora.

Por outro lado, se o professor pede que o aluno descreva um fenômeno científico observado, em formato narrativo (não estamos nos referindo àqueles tradicionais relatórios longos e excessivamente técnicos), em textos rápidos, em que apareça a forma organizacional da maneira como o aluno está compreendendo o fenômeno, então será possível ter um bom diagnóstico do que fazer para ensinar melhor tanto o conceito científico quanto o ato de ler e escrever. Aqui vale a pena citarmos novamente Roland Barthes (2004, p. 231): "A escrita, por oposição à escrevência de discursos, é um tipo de prática graças a qual dissolvemos os imaginários de nossa linguagem. Constituímo-nos em sujeitos psicanalíticos ao escrever".

Nesse contexto, as semelhanças entre o processo de alfabetização e o ato de ensinar Ciências advêm, portanto, da resposta à própria pergunta acerca de como ensinar Ciências.

\section{Considerações finais}

Ao ensinarmos Ciências, é preciso explicitar etapas, como: a observação de um fenômeno em que o conceito científico está envolvido, sua generalização, sua distinção e peculiaridade em relação aos demais conceitos, a tentativa de encontrar lógica em uma maneira de pensar distante, muitas vezes, do senso comum, suas limitações, entre outras ações. Em Ciência, o rigor nesse processo, de maneira a fazer o aluno ler aquele fenômeno com um outro olhar, costumeiramente embrenhado de maior sutileza, é o que o faz aproximar-se do que está sendo ensinado. Uma vez munido desse rigor, fruto de um desenvolvimento da capacidade de concentrar-se, interiorizar-se, refletir, o aluno poderá ter mais segurança para lidar com suas angústias e com o desconforto psicológico gerado pela falta de clareza do que ocorre ao seu redor (como afirmou Barthes a respeito de um bom domínio do código). Ou seja, talvez esteja mais preparado para lidar com as características da sociedade pós-industrial.

Se lhe for solicitada uma produção escrita (não somente uma "escrevência" - para utilizarmos um termo de Barthes), o aluno se verá diante de quanto aprendeu sobre o fenômeno estudado, escolherá quais as melhores palavras para descrevê-lo, organizar-se-á mentalmente para poder explicá-lo de maneira clara - o que significa, muitas vezes, reconstituir o fenômeno estudado, enfim, apreenderá o fenômeno e, mais do que isso, mostrará, de maneira mais evidente, suas possíveis lacunas ou incompreensões acerca daquele conhecimento. 
As possíveis contribuições do ensino de ciências ...

É provável que ensinar Ciências com essa perspectiva favoreça o diálogo - entre o conhecimento dos alunos e o tema a ser trabalhado, entre professor e alunos, e entre alunoaluno, e que, com isso, seja possível ampliar a visão de mundo inicial dos alunos, aproximandoa da visão científica, permitindo aprimorar a alfabetização, papel de todos os envolvidos no Fundamental II.

\section{Referências}

ALMEIDA, M. J. P. M.; RICON, A. E. Divulgação científica e texto literário: uma perspectiva cultural em aulas de física. Caderno Catarinense de Ensino de Física, Florianópolis, v. 10, n. 1, p. 7-13, 1993. Disponível em: <http://journal.ufsc.br/index.php/ fisica/article/download/9791/15138>. Acesso em: 22 out. 2013.

ALMEIDA, M. J. P. M.; SILVA, H. C. O funcionamento de textos de divulgação científica: gravitação no ensino médio. In: ENCONTRO DE PESQUISA EM ENSINO DE FÍSICA, 6., 1998, Florianópolis. Resumos... São Paulo: SBF, 1998. p. 1-11.

AMARAL, M. G. T. Encontro com professores e alunos de uma escola estadual de ensino médio: uma escuta em que a dimensão objetiva se vê alinhavada pela subjetividade dos atores. In: AMARAL, M. (Org). Educação, psicanálise e direito: combinações possíveis para se pensar a adolescência na atualidade. São Paulo: Casa do Psicólogo, 2006. p. 78-99.

O espectro de Narciso na modernidade: de Freud a Adorno. São Paulo: Estação Liberdade: FAPESP, 1997.

AULETE, C. idicionário Aulete. [S. 1.]: Lexikon, 2008. Disponível em: < http://aulete.uol. com.br/site.php?mdl=aulete_digital\&op=loadVerbete\&pesquisa $=1 \&$ palavra $=$ identidade $>$. Acesso em: 23 jun. 2013.

BARTHES, R. O grão da voz. São Paulo: Martins Fontes, 2004.

BEISIEGEL, C. R. Ação política e expansão da rede escolar. Pesquisa e Planejamento, São Paulo, n. 8, p. 99-197, 1964.

A qualidade do ensino na escola pública. Brasília: Liber, 2006. 168p.

Questões de atualidade na educação popular: ensino fundamental de jovens e adultos analfabetos ou pouco escolarizados. Educação em Revista, Belo Horizonte, n. 31, p.7-19, 2000. Disponível em: <http://educa.fcc.org.br/pdf/edur/n31/n31a02.pdf >. Acesso em: 22 out. 2013.

BRASIL. Ministério da Educação e do Desporto. Secretaria de Educação Fundamental. Parâmetros curriculares nacionais: terceiro e quarto ciclos do ensino fundamental. Brasília, 1998. $10 \mathrm{v}$.

- Ministério da Educação e do Desporto. Secretaria de Educação Média e Tecnológica. Parâmetros curriculares nacionais: ensino médio: bases legais. Brasília, 1999. 
Silva, J. A.

Presidência da República. Lei $\mathbf{n}^{\circ}$ 9.394, de 20 de dezembro de 1996. Estabelece as diretrizes e bases da educação nacional. Brasilia, 1996. Disponível em: <http:// www.planalto.gov.br/ccivil_03/leis/19394.htm>. Acesso em: 22 out. 2013.

CASARIN, K. As diferenças entre os desempenhos escolares, a relação com os saberes e o acesso à escrita: o que dizem professores e alunos de 5. série. $2008.128 \mathrm{f}$. Dissertação (Mestrado em Educação) - Instituto de Biociências, Universidade Estadual Paulista, Rio Claro, 2008.

CHASSOT, A. Alfabetização científica: questões e desafios para a educação. Ijuí: Ed. Unijui, 2000.

CRITELLI, D. Martin Heidegger e a essência da técnica. Margem, São Paulo, n. 16, p. 83-89, 2002. Disponível em: <http://www.pucsp.br/margem/pdf/m16dc.pdf>. Acesso em: 22 out. 2013.

DEBORD, G. A sociedade do espetáculo: comentários sobre a sociedade do espetáculo. Rio de Janeiro: Contraponto, 1997.

FREIRE, P. Pedagogia da autonomia. Rio de Janeiro: Paz e Terra, 1996.

HABERMAS, J. O discurso filosófico da modernidade. São Paulo: Martins Fontes, 2002.

KAWAMURA, M. R. D.; SALEM, S. O texto de divulgação e o texto didático: conhecimentos diferentes? In: ENCONTRO DE PESQUISADORES DE ENSINO DE CIÊNCIAS, 5., 1996, Águas de Lindóia. Anais... São Paulo: SBF, 1996. p. 588-598.

LIPOVETSKY, G. O crepúsculo do dever: a ética indolor dos novos tempos democráticos. Lisboa: Dom Quixote, 1994.

A era do vazio. São Paulo: Antropos, 2002.

. As marcas se tornaram o sentido da vida das pessoas. Cult, São Paulo, v. 10, n. 120 , p. 10-17, dez. 2007b.

A sociedade da decepção. Barueri: Manole, 2007a.

. A sociedade pós-moralista. Barueri: Manole, 2005.

Os tempos hipermodernos. São Paulo: Barcarolla, 2004.

MELO, J. R.; ROTTTA, J. C. G. Concepção de ciência e cientista entre estudantes do ensino fundamental. In: ENCONTRO NACIONAL DE ENSINO DE QUÍMICA, 15., 2010, Brasília. Anais... Brasília: UnB, 2010. Disponível em: <http://www.xveneq2010.unb.br/ resumos/R0215-1.pdf>. Acesso em: 23 jun. 2013.

MENEZES, L. C. Uma educação básica para o novo século. São Paulo: IF-USP, 2005.

. O novo público e a nova natureza do ensino médio. Estudos Avançados, São Paulo, v. 15, n. 42, p. 201-208, 2001. Disponível em: <http://dx.doi.org/10.1590/S0103$40142001000200008>$. Acesso em: 22 out. 2013. 
As possíveis contribuições do ensino de ciências ...

Rever o quê, mudar por quê? Acesso: revista de educação e informática, São Paulo, n. 14, p. 29-34, 2000. Disponível em: < http://www.crmariocovas.sp.gov.br/pdf/ acesso_14_p029-034_c.pdf >. Acesso em: 22 out. 2013.

MENIN, A. M. C. S. Formação de professores e o fracasso escolar na 5. série do período noturno. 1994. 174 f. Dissertação (Mestrado em Educação) - Faculdade de Filosofia e Ciências, Universidade Estadual Paulista, Marília, 1994.

PÉREZ, D. G. et al. Para uma imagem não deformada do trabalho científico. Ciência $\boldsymbol{\&}$ Educação, Bauru, v. 7, n. 2, p. 125-153, 2001. Disponível em: < http://dx.doi.org/ 10.1590/S1516-73132001000200001>. Acesso em: 22 out. 2013.

SAGAN, C. A anticiência. In: O mundo assombrado pelos demônios: a ciência vista como uma vela no escuro. São Paulo: Companhia das Letras, 1996. p. 244-262.

O mundo assombrado pelos demônios: a ciência vista como uma vela no escuro. São Paulo: Companhia das Letras, 1996.

SILVA. J. A. Cidadania e divulgação científica no ensino de física. 2002. 159 f. Dissertação (Mestrado em Ensino de Ciências) - Instituto de Física, Universidade de São Paulo, São Paulo, 2002.

Compromisso e paixão: o universal e o singular na boa escola pública. 2008. 310 f. Tese (Doutorado em Educação) - Faculdade de Educação, Universidade de São Paulo, São Paulo, 2008.

A sociedade pós-industrial e os objetivos do ensino médio e do ensino de física. In: ENCONTRO DE PESQUISA EM ENSINO DE FÍSICA, 13., 2011, Foz do Iguaçu. Resumos... Disponível em: <http://www.sbf1.sbfisica.org.br/eventos/enf/2011/sys/ resumos/T0371-1.pdf>. Acesso em: 22 out. 2013.

SILVA, M. H. G. F. D. Passagem sem ritos: as quintas séries e seus professores. Campinas: Papirus, 1997.

SIMÕES, C. A.; SIMÕES, A. V. As representações sociais do cientista entre alunos do ensino fundamental de Manaus: indicações para o ensino de Ciências. In: ENCONTRO NACIONAL DE PESQUISA EM EDUCAÇÃO EM CIÊNCIAS, 7., 2009, Florianópolis. Atas... Florianópolis: ABRAPEC, 2009. Disponível em: <http://posgrad.fae.ufmg.br/ posgrad/viienpec/pdfs/1198.pdf ý>. Acesso em: 23 jun. 2013.

TEIXEIRA, A. Educação no Brasil. 3. ed. Rio de Janeiro: Ed. da UFRJ, 1999.

ZANETIC, J. Literatura e cultura científica. In: ALMEIDA, M. J. P. M. de; SILVA, H. C. da. (Org.). Linguagens, leituras e ensino da ciência. Campinas: Mercado de Letras, 1998. p. 121-130.

Artigo recebido em 16/01/13. Aceito em 15/10/13. 